Volume 7, Issue 4, 763 - 774.

ISSN: 2165-8714

http://www.eu-jer.com/

\title{
The Perceptions of Students about the Role of School Counselors on Career Selection
}

\author{
Egemen Hanımoğlu * \\ Cukurova University, TURKEY
}

Received: July 4, $2018 \cdot$ Revised: September 1, $2018 \cdot$ Accepted: September 10, 2018

\begin{abstract}
Firstly, the researcher provides an insightful introduction into the phenomenon focused on to explicate the learners' views about the role of school counselors in line with career selection. To attain the study objectives, the researcher used a multi-unit case study to investigate the perceptions among high-school students about school counselors' roles and career selection. The investigator used open-ended questionnaires to harness information and then utilized the qualitative descriptive approach to analyze the data. Analysis of the information collected via open-ended questionnaires was done through thematic analysis, which was a subset of the broader qualitative descriptive technique. The findings denoted that high-school learners have varied perceptions with regards to the roles of school counselors and career selection.
\end{abstract}

Keywords: Guidance and counseling, career, career selection, counselor, high school.

To cite this article: Hanımoğlu, E. (2018). The perceptions of students about the role of school counselors on career selection. European Journal of Educational Research, 7(4), 763-774. doi: 10.12973/eu-jer.7.4.763

\section{Introduction}

The modern education systems are anticipated to aide learners to develop emotionally, socially, intellectually, and physically (Karatas \& Kaya, 2015). Counselors help the students to develop and make informed decisions including career selection. In perspective, the Turkish system of education offers students an array of personnel services that bolster their academic attainment and foster improvement in other varied aspects. According to Oertle and O'Leary (2017), guidance entails services that help students in solving problems, making decisions, improving capacities, and acting responsibly. The individuals that offer and maintain professional counseling services are school counselors and other qualified experts. Goodman-Scott and Grothaus (2017) elucidate that the roles of counselors have evolved and have since included mental health counseling, evaluation and psychometrics, career guidance, coordination, collaboration, and education among others. According to Karatas and Kaya (2015), counselors establish vital psychological relationships with individual learners, which help in maintaining their respective development, decisionmaking, and solving problems.

Todd Mckee and Caldarella (2016) depict that dropping out of school often results in poverty, unemployment, high dependency, and low quality of life among other social difficulties that call for effective career guidance in schools. According to Awinsong, Dawson, and Gidiglo (2015), making realistic and correct career choices is a delicate and difficult task; hence, schools ought to ensure that guidance and counseling with regards to career selection is effective to foster appropriate decision-making. Whether learners utilise the services offered by school counselors depends on the learners' perceptions about the roles of counselors when selecting their career (Awinsong et al., 2015). Andronic, Andronic, Lepadatu, and Tatu (2013) indicate that counseling incorporates an array of things because it is both an evaluation and a method of information. Counseling is a technique to change an individual's behavior, it is a communication experience, and it is a way of searching for meaning in life (Andronic et al. 2015).

\section{Statement problem}

Nyamwange, Nyakan, and Ondima (2012) indicate that services that focus on guidance and counseling enhance the learners' success, especially with regard to career selection. However, delivering the guidance and counseling sessions face a myriad of challenges, which hinder effectiveness of guiding the students to select their future careers. According to Nyamwange et al. (2012) several challenges affect guidance and counseling with regards to career selection. These challenges include inadequate programs with regards to guidance and counseling, inadequate resources, and

\footnotetext{
* Correspondence:

Egemen Hanimoglu, Cukurova University, Faculty of Education, Adana, Turkey.

Email: ehanimoglu@gmail.com
} 
insufficient support for the counseling programs among others. Lai-Yeung (2014) contends that counselors have multiple roles to achieve. Barden, Sherrell, and Matthews (2017) suggest that to accomplish the counseling roles in a professional manner, the counselors should be competent with regards to attaining the learners' interests. In essence, the perception of the students with regards to the role of the school counselors affect the aspect of career counseling; thence, the vitality to investigate how learners perceive the role of school counselors.

Aim

The researcher aimed at exploring the perceptions of learners regarding the role of school counselors on the aspect of career selection.

Objectives

i. To investigate the perceptions of students about the role of school counselors in Adana, Turkey

ii. To explore the challenges that face career selection among learners at Adana, Turkey

\section{Study questions}

i. What are the perceptions of students about the role of school counselors in Adana, Turkey?

ii. What are the challenges facing career selection among students at Adana, Turkey?

\section{Significance of the research}

The research investigates the perceptions of the learners about the role of school counselors at Adana, Turkey. The primary significance of this study is to reveal vital information that could inform all the stakeholders in learning to identify and recognize the roles of counselors in students' career selection. In this regard, parents, schools, and students can better understand the benefits of school counselors on students' career selection, relative to the learners' point-ofview. Furthermore, the research findings will assist in understanding the students' opinions regarding the assistance given by counselors' during career selection. As a result, the school can formulate better practices for enhancing the effectiveness of counselors' involvement in students' career selection. For instance, through this study, the school and parents can understand the benefits and drawbacks of counselor-assisted students' career selection; this would help perfect the practice. The findings of this study also act as a secondary source of information for future studies in the relevant field.

\section{Overview of Career Counseling in Schools}

Novel research has indicated that school provides an appropriate setting for students to explore and improve career efficacy (Glessner, Rockinson-Szapkiw, \& Lopez, 2017). Career management is a core concept among students as they expect to be employed and be required to perform with regard to their personal interests and personalities. As such, Todd (2017) argues that there is a need for a proper career counseling to ensure that the learners develop an understanding of what they want in life. A viewpoint held by Maxey and Kezar (2016) indicate that a detailed planning regarding career selection could aid the students in choosing respective study programs that are aligned to individual vocation. Glessner et al. (2017) contend that recent trends in high education depict the necessity to customize programs to align with the labor market. Further, learners need to start career planning before they undertake various degrees so that they establish compatibility with regards to the types of employment desired (Palade \& Constantin, 2012). In that regard, students ought to benefit from career counseling, which ensure that they plan before-hand.

In most parts of the world including Turkey, students select subjects that they find suitable for their future careers. The situation is often difficult for students; hence, the need to advise them accordingly with respect to their desired careers. Solving this problem requires professional counseling in careers to ensure that the learners have wide knowledge before choosing a career. Professional career counselors offer appropriate guidance that are specific to individuals after assessing and testing a learner's intelligence, skills, personality, and interests. There are several factors that affect a learner's choice of career; hence, it is vital to guide the learners to make informed and appropriate decisions regarding their future career.

\section{The Functions and Roles of Counselors in Schools}

Vocational and counseling guidance are both practical and theoretical techniques emanating from social pressures due to the industrial development (Patton \& McMahon, 2014). The situation led to a shift in the association between the demand and supply of work with an increased expectation of high level of skills among graduates (Pârvu \& Mitran, 2017). Further, young people experience issues with adolescence; hence, need guidance to transition while harmonizing their interests, skills, and aspirations. Therefore, vocational and guidance counseling is imperative for the students to identify their future professions and develop towards attaining an optimal quality of life. A study conducted by Pârvu and Mitran (2017) examined the vocational and counseling performance measurement activities that were implemented in pre-university education. They indicate that for several years, career guidance and counseling centers in Romania were insufficient in educational settings. However, due to funding from Europe, the centers have been established to guide the students on career paths. 
Stăiculescu, Livinţi, Stefan, Todea, and Albu (2017) studied the aspect of managing the necessity of counseling and career guidance among the students. They conducted a case study at the Bucharest University of Economics and Studies where they discussed the need for management of counseling and career guidance among the students. The researchers indicate that selecting the right profession and then progressing through the required steps to be a specialist is a sophisticated endeavor. However, school counselors tailor the counseling and career guidance programs in such ways that they can provide various benefits to the society, community, and individual learners. Basically, school counselors provide the necessary support towards professional development with regards to the students' abilities and aspirations; they reduce dropouts, foster transition in different education levels, enhance participation, bolster social inclusion, and ensure accessibility to the labor market.

Mapfumo and Nkoma (2013) studied the counseling and guidance received by students in both high school and university. The study included freshmen learners. The researchers were focused on determining the services of guidance and counseling the students taking social sciences in a university in Zimbabwe received in high school and those they desired when starting their university education. Mapfumo and Nkoma (2013) noted that the variations evinced among the respondents sorted with regards to the type of schools the students attended. The researchers utilized a survey design of completing research and fielded self-administered questionnaires that contained closedended questions among the first years after their second month in the university. Ninety respondents; 41 male and 49 females volunteered via consenting to provide feedback. T-test, bar graphs, and chi-square were implemented for analysis and the findings indicated that counseling and guiding are vital among the learners. However, there was no noteworthy difference between the female and male students but the female learners showcased favorable replies compared to their male counterparts.

\section{The Perceptions of Students about Counselors}

In the contemporary ICT world, systems and society have become sophisticated coupled with the introduction of novel and optimal professions. As such, there is a need for career counseling among students, especially those in Adana, Turkey. Malik and Kiran (2012) studied the perceptions of learners regarding the necessity of counseling them on career selection at the university level. The investigators used descriptive research to examine the need for career counseling and align the study to its objectives. Six departments were chosen as a sample from the public with 171 respondents. The researchers developed the questionnaires to garner information. Accordingly, the learners realized the need for career counseling with regards to the selection of appropriate courses for future careers. Further, it was established that female students favored counseling services compared to their male counterparts.

Ozabaci (2011) investigated the metaphorical conceptualizations of the Turkish students with regards to school counselors. According to Ozabaci (2011), metaphorical language is utilized as a tool to automatically express how individuals experience the world around them and themselves. Ozabaci (2011) asserts that metaphors offer a novel understanding and structure about the people's actions and thoughts. The purpose of the study undertaken by Ozabaci (2011) was to explore the secondary school learners' conceptual metaphors aimed at engaging counselors to evaluate students' beliefs regarding counseling and support constant evolution and change of metaphors to represent and reflect the counseling principles. The researcher carried out the study among 1,125 learners selected from a school in Turkey. To ascertain the learners' perceptions with regards to their school counselors, the students were requested to complete a given sentence "School counselors are lie...because..." afterwards the researcher assigned the statements/metaphors outlined to 6 classes including a) Counselors as earnest and sincere people, b)counselors as tutors and developers, c) counselors as advisors and elucidators, directive individuals, d) counselors as healers, e) counselors as goody, and f) counselors as nurture. The results strongly depict that school counselors have the potential to utilize metaphor analysis to aid learners in examining their beliefs, values, and philosophies with regards to guidance and counseling.

\section{Influence of the counselor's gender on the perceptions of the students on school counselors}

Yilmaz-Gozu (2013) instigated a study that examined the impact of counselors' gender and types of problem on attitudes of finding help among high school learners in Turkey. The study scrutinized gender differences in finding aid and the types of problems among the students in Turkey. Yilmaz-Gozu (2013) implemented the study using a survey and "The Attitudes towards Seeking Help Scale" to elucidate the counselors' gender effects among learners that seek guidance and counseling services. The researcher administered the questionnaires and the attitudes help scale among 342 student-adolescents (Yilmaz-Gozu, 2013). Further, the investigator used ANOVA to depict that female and male learners displayed varying help-seeking beliefs with regards to the gender of the school counselors. The findings implicate that female learners have more positive attitudes compared to the male students. In essence, for the female students, neither problem-type nor gender of the counselors affected their interactions and help-seeking conceptions (Yilmaz-Gozu, 2013). However, for the male students, the type of problem experienced and the gender of the counselors significantly affect their interaction and help-seeking behavior.

Another study implemented by Snell Jr, Hampton, and McManus (2012) explored the effects of participant and counsellor gender on the willingness to express themselves and disclose relationships. Snell Jr et al. (2012) connote that many researchers have delved into the issues concerning counseling including counselor's gender, client gender, 
and counselor-client gender pairings. The researchers accomplished their study objective among 431 students who indicated how the gender of counselors affects their disclosure. The examiners required that the students discuss about 25 topics related to the relationships as determined by the Relationship Disclosure Scale with both male and females. The findings suggest that the willingness of the students to open up and discuss relationship-related issues, especially intimate relationship depend on the counselor's gender, their own genders, and the specific topics selected. Additionally, many personality variants such as relational consciousness and relational-esteem associated with the willingness of females to discuss with both male and female counselors. However, Snell Jr. et al. (2012) concluded that the gender of the counselors does not significantly affect the perceptions of the students with regards to the role of the school counselors and career selection.

\section{Theoretical Framework}

Tang (2008) ascertains that the vocational choice theory postulated by Holland in 1997 has enormously impacted the ideologies of career counseling, vocational theories, and career assessment. According to Holland, congruence between an individual's vocational interests, personalities, and the environment result in job satisfaction and tenure. The personal career theory as evinced by Reardon and Lenz (1999) depict that people often have beliefs, assumptions, ideas, and knowledge, which guide them with regards to choosing careers. Through the personal career model, counselors can draw on the learners' personality traits to guide them appropriately on selecting careers. Thus, the personal career theory will be used to align how the learners perceive the role of the school counselors with regards to career counseling provided that they (students and other people alike) have different beliefs, ideas, and knowledge that guide them in making career-related decisions.

\section{Method}

\section{Research Design}

The study adopts a case study design, which involves investigating the phenomenon in a narrowed and specific population. In this research, the population is narrowed down to selected schools in Adana, Turkey. Hence, the study will be based on the case in Adana, where counselors are involved in the students' career selection. The case study design is appropriate for this study since it is flexible and focuses on the reality within a specified case or population. Besides, the design is highly simplified since the population is not sparsely populated; this eliminates the additional costs of research such as transportation and time. According to Ridder (2017), case studies can focus on groups, individuals, organizations, events, an anomaly or a problem. Besides, when conducting a case study, the researcher can delve in-depth with regards to the aspect considered. Similarly, case studies offer a variety of sources from which to obtain information for analysis. Therefore, through focusing on the case of Adana Schools that practice counselorassisted students' career selection, sufficient data will be gathered about the perceptions of students about the role of school counselors on career selection.

\section{Participants and selection techniques}

The study was conducted at Adana, Turkey. The researcher selected three schools through stratified sampling whereby all the schools in Adana were categorized into strata based on the counselors' involvement in career selection. Within the strata of schools practicing counselor-assisted career selection, three schools were randomly selected for the study. In this case, the three schools selected were assumed as a sufficient sample population for the study. Hence the schools sampled include Adana Anatolian High School, Piri Reis Anatolian High School, and ATO Anatolian High School. All the three schools were allowed to provide 60 students eligible for career selection and are in 11th and 12th Grades respectively. Hence, the total study population is 60 students, with an equal number of males and females.

\section{Developing an Interview form and collection of data}

The study utilized a self-report questionnaire, which was designed by the researcher. The self-report questionnaire requires the respondents to read the questions and offer responses without any form of involvement, guidance, or influence from the researcher. Besides, the method is appropriate when gathering opinions, perspectives, or feelings of the participants towards the phenomenon. In the selection of the appropriate method of data collection, a pilot interview was performed with two experts in studies involving learning institutions. Both the experienced experts/consultants recommended the use of the self-report questionnaire as the best approach for gathering valid data from learners.

Bird (2009) contends that a questionnaire is a favorite and essential tool for harnessing information regarding perceptions about natural issues and public knowledge. The survey involved purely open-ended questions, which are suitable for qualitative analysis. Besides, using closed-and-open-ended questions give the respondents the freedom to indicate their responses and explain them adequately without third-party influence or fear of victimization (Hsieh \& Shannon, 2005). The questionnaire had 15 questions including the age and grade the learners belonged. The 15 questions were extracted from the two main research questions. The closed-ended questions were on Likert-scale and mostly focused on introducing the participants to the topic of study. The 15 questions were determined based on three that familiarize the respondent to the topic, then four closed-ended questions for identifying the grade, gender, and 
opinions on whether counselor-assisted career selection is appropriate. The remaining questions were open-ended and were determined based on the ability to source reflections, perceptions, and views of the participants.

\section{Data analysis}

The study implemented a qualitative descriptive approach focused on identifying the common themes to clarify the perceptions of students about the roles of the school counselors in career selection. In this approach, the data gathered through the self-report questionnaires are assessed and coded; this involves reading all the transcripts and categorizing based on standard features/responses, gender, and any other variable preferred. Due to the value of data coding, the researcher sourced the help of other peers, to help read all the 60 transcripts and categorize them accordingly. According to Hsieh and Shnnon (2005), the approach seeks to comprehend and classify a large amount of data that identify with the past meaning; this may require proper personnel to ensure accuracy. After coding, the responses on respondents' reflections and insights were identified and noted on a separate sheet. The qualitative analysis focuses on the categorization and interpretation of the feedback to obtain statements about the explicit and implicit dimensions of the information with regards to making meaning. Within the insights and reflections extracted, similar themes, phrases, and patterns were identified; these are then listed and verified across and within the data. In this regard, the data analysis focused on drawing themes for presentation and interpretation. Additionally, the themes are further explained and supported by theories to derive detailed findings of the study.

\section{Reliability and Validity}

The generalizability of the research findings to a broader population depends on the reliability and validity. In this regard, results without proper validity and reliability are considered vague and not applicable to the larger society. In this study, validity and reliability were achieved in various ways including seeking participant confirmation through an official process. The letters of consent were officially prepared and signed to authorize the students' participation. Additionally, the questionnaires had straightforward and relevant questions, which did not allow room for irrelevant responses that affect the validity of the findings. During the coding process, qualified qualitative data analysts were sourced to enhance detailed scrutiny of all the transcripts and eliminate errors and omissions when one person codes all the 60 sheets. Consequently, satisfactory reliability originates from experts-assisted coding and use of electronic equipment to enhance accuracy.

During the data collection process, all the counselors linked to career selection were excluded from any form of involvement. Hence, the data were collected through printed and official self-report questionnaires, which were administered during the particular time allocated for the research. In this regard, the respondents were not allowed to collude with third-parties but were encouraged to ensure sincerity and openness under the confidentiality agreement. Therefore, by eliminating all the biases and causes of errors during the sampling, data collection, and analysis; the validity and reliability of the findings was attained.

\section{Ethical concerns}

Conducting a study that involves human participants, demands that the researcher highlight the relevant ethical considerations and how to handle them. Through a consent form developed by the researcher, the participants had a chance of reviewing the questions before the actual data collection exercise. The consent form was designed and questions attached for perusal. In the consent form, the researcher explained that responding to the questionnaire is voluntary and that incentives will not be provided. The participants retain the freedom to partake in the study and withdraw at will and at any time during the study. Further, the information collected will be kept confidential and no unauthorized persons will gain access. Besides, the researcher assured the participants that participating in the study does not pose harm and anyone that feels uncomfortable can withdraw even during the study process.

\section{Results}

\section{Response rate}

The researcher fielded 60 questionnaires to students in both grade 11 and 12 in the three selected schools. Indicatively, the researcher sent 20 questionnaires to each school and they were divided equally between the $11^{\text {th }}$ and the $12^{\text {th }}$ grades. Figure 1 illustrates the number of questionnaires obtained. Accordingly, 14 questionnaires were collected from Adana Anatolian High School, 16 from Piri Reis Anatolian High School, and 19 from Ato Anatolian High School respectively. As such, the response rate was $81.67 \%$. There was a high response rate, which means that the data obtained is representative of the sample selected. 


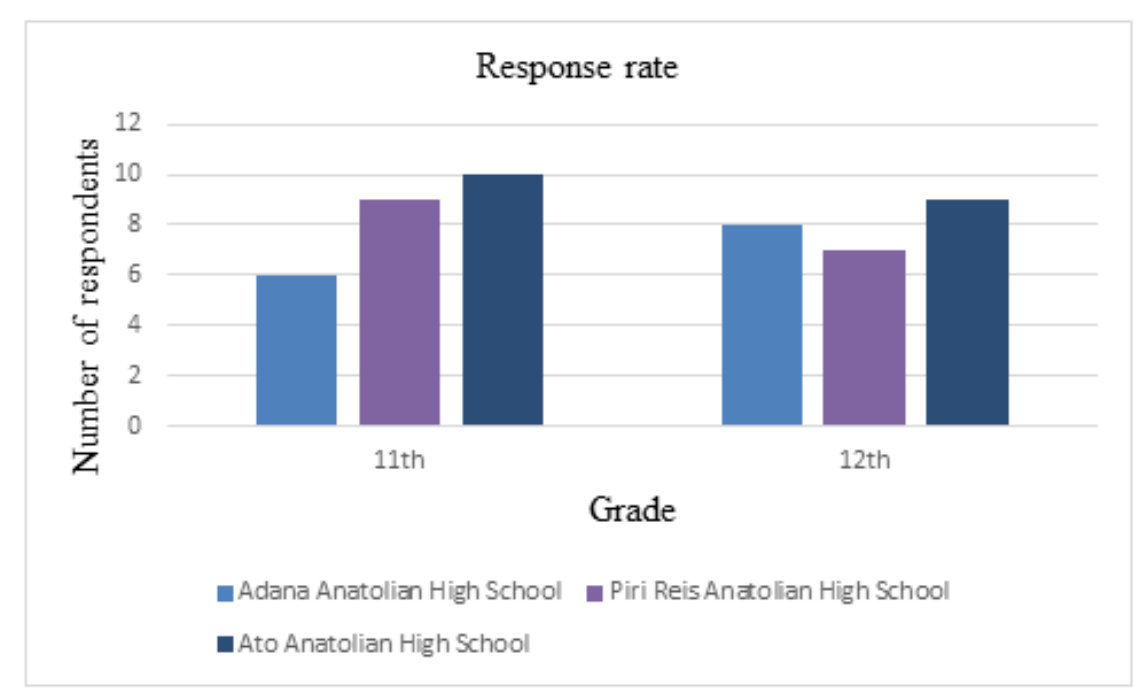

Figure 1: Response rate

Sex of the respondents

Figure 2 illustrates the sex of the students that participated in the data garnering exercise. There was a total of 49 questionnaires obtained from the three schools. Out of the 49 responses, the males were 28 and represented $57 \%$ of the total feedback. The females were 21 and indicated $43 \%$ of the total responses harnessed.

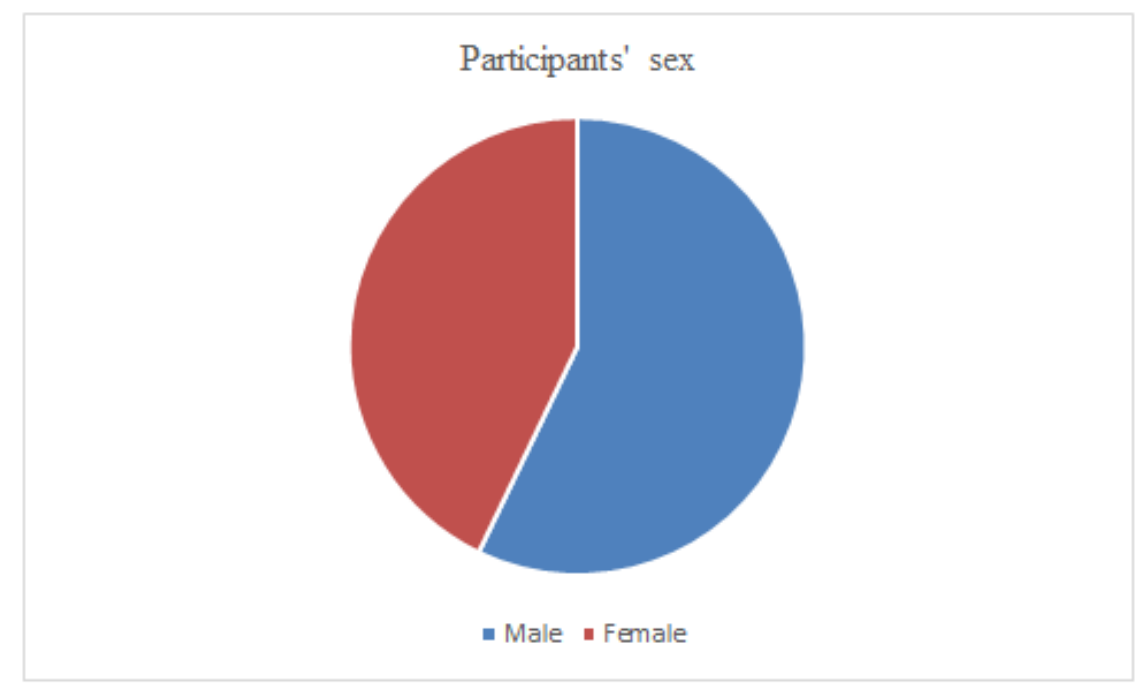

Figure 2: Participants' sex of the respondents

The 49 respondents provided feedback to the questionnaires fielded. Figure 3 represents the ages of the learners targeted and how they responded to the questionnaire provided. Basically, there were 25 students from the 11 th grade and 24 participants from the 12th grade respectively. Accordingly, the learners in the 11 th grade were 17 years and those in the 12th grade were 18 years correspondingly. In lieu of these ages, the students that provided feedback with regards to their ages represented $51 \%$ and $49 \%$ respectively. 


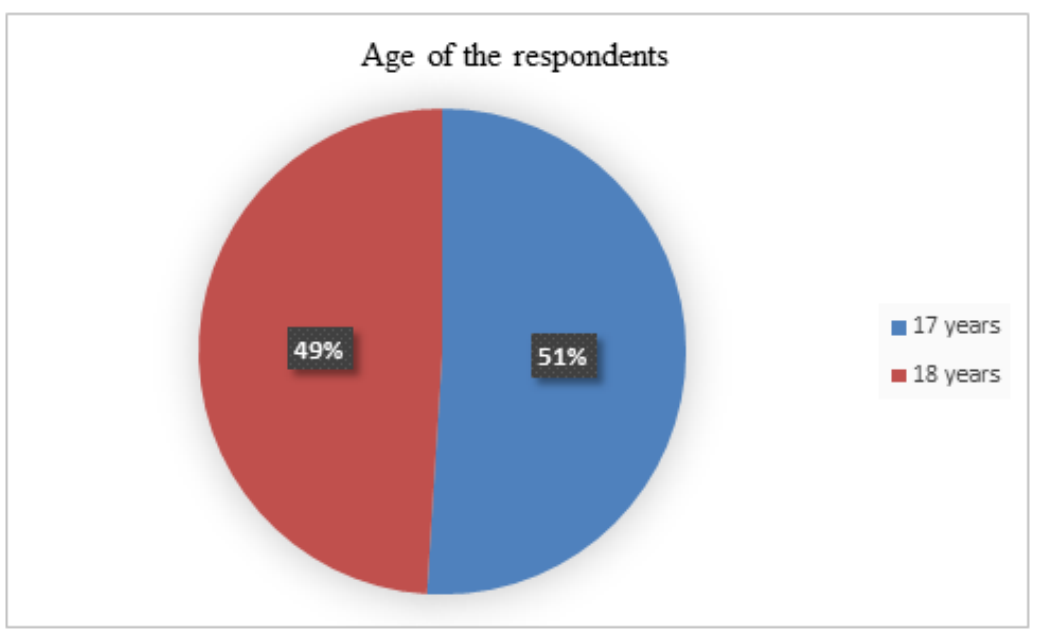

Figure 3: Respondents' ages Themes

Vaismoradi, Jones, Turunen, and Snelgrove (2016) ascertain that there is adequate knowledge regarding the definition, differences, and details of qualitative thematic analysis as a technique to qualitative descriptive studies. Vaismoradi et al. (2016) indicate that thematic analysis is categorized under the aspect of qualitative descriptive design to analyze textual information and explicate relevant themes. Thematic analysis as a technique of qualitative descriptive design systematically codes, examines meaning, and provides descriptions with regards to the social reality via theme creation (Vaismoradi et al., 2016).

After the arduous exercise of drawing themes from the information collected, the researcher identified 5 relevant themes with regards to the roles of counselors in career selection among the learners. The themes identified included: Friendliness and approachability, comprehension of the learners' viewpoints, promptness of counselors to the learners' requests, dependability to keep promises, and robustness in vocational knowledge.

\section{Friendliness and approachability}

Friendliness and approachability of the school counselors is a vital component towards successful career counseling (Shi, Liu, \& Leuwerke, 2014). In lieu of this perspective, the researcher sought to understand the perceptions of students with regards to approachability and friendliness of their school counselors. According to the feedback obtained, 36 respondents ascertained that their respective school counselors are friendly and approachable. The figure indicating that school counselors are approachable and friendly represented $73.5 \%$ while those depicting them as unfriendly and unapproachable was 13 and represented 26.5\%. Figure 4 indicates those students that said that their counselors are approachable and friendly.

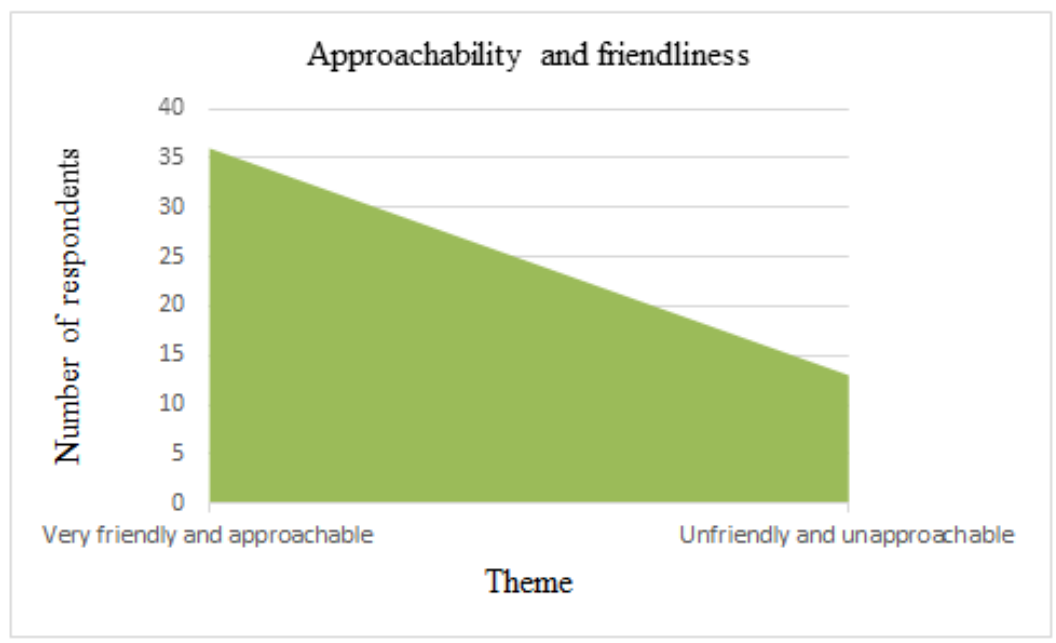

Figure 4: School counselors' approachability and friendliness

A study conducted by Owino (2013) sought to establish the nature of counseling services among learners in secondary level schools in Eldoret, Kenya. In her study study, Owino (2013) set to determine how approachability and friendliness affect the aspect of guidance and counseling with regards to career selection. Notably, Owino (2013) ascertains that learners face challenging situations; hence, counseling services should accommodate them and should focus on the students' improvement of personal, educational, civic, vocational, and social adjustment. These findings are in line with the results of the current study indicating that approachability and friendliness of the school counselors fosters the 
help-seeking behavior of the students and ensures better career selection. Further, Shi, Liu, and Leuwerke (2014) affirm that since the learners face numerous difficult situations, they ought to be presented with a favorable environment to enhance their mannerisms in seeking guidance both to their personal lives and career selection. Thus, it is clear that majority of the students (73.5\%) who responded to the study questionnaire perceived their school counselors as approachable and friendly.

\section{Comprehension of the learners' viewpoints}

School counselors are experts that guide the students regarding their academic goals, personal, lives, career selection, and health among other roles (Shillingford-Butle, Patel, \& Ngazimbi, 2012). Due to the diverse roles played by these school counselors, it is imperative that they have the much-needed knowledge and skills to comprehensively understand the learners' different views. These findings are retaliated by Stefaniak and Tracey (2015) who ascertain that students have different experiences; hence, their needs must be understood for an effective career counseling session. The current investigation revealed that school counselors have comprehensive knowledge about the varied students' views with regards to counseling and career selection. Accordingly, 28 participants indicated that the school counselors have a vast understanding of their students' viewpoints and represented $57.1 \%$ of the total responses. Those who perceived the counselors as not having a robust understanding of the learners' views were 21 and implicated $42.9 \%$. Figure 5 represents this information pictorially indicating both the 28 and 21 of the respective responses.

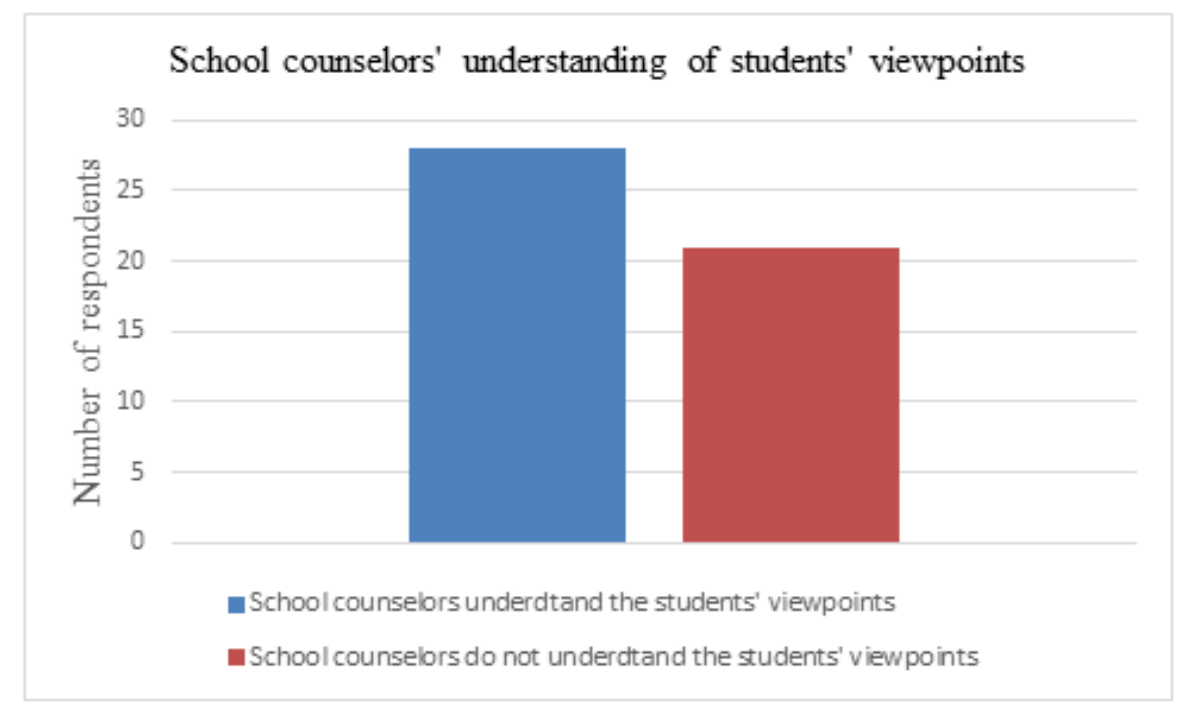

Figure 5: Counselors' comprehension of the learners' viewpoints

Aligning these findings to the extant literature, Atici (2014) concedes that school counselors ought to have a tacit comprehension of the different views of the students so that they can effectively provide guidance and counseling along with career selection services. Evidentially, the findings of the extant study align with the verdicts of Shillingford-Butle, Patel, and Ngazimbi (2012), Atici (2014), and Stefaniak and Tracey (2015) indicating that counselors are professionals that are trained to guide and counsel students. Therefore, they ought to have an in-depth understanding of the different views held by learners so that they can effectively guide their clients.

\section{Promptness of counselors to the learners' requests}

Students are often faced with varied issues, which they require prompt solutions (Awinsong et al., 2015). Awinsong et al. (2015) studied the students' perceptions about the counselors' roles in career selection. The study was undertaken in Ghana at Mfantseman Municipality. The findings of Awinsong et al. (2015) study established that guidance and counseling is key to career selection decision-making processes. Therefore, the professional counselors ought to respond promptly to the students' needs. The study by Awinsong et al. (2015) also revealed that characteristics of school counselors and other varied factors often contribute to the promptness of responding to the students' needs. The participants in the current research indicated that majority (81.6\%) of the school counselors respond promptly to the students' requests and needs. From the responses received, it was explicit that $81.6 \%$ of the respondents perceive the school counselors as responding promptly to their needs and requests. Those that perceived the counselors as not responding promptly were only 9 and implicated $8.4 \%$ of the total feedback. Figure 6 represents the promptness of the school counselors with regards to the students' needs and requests. 


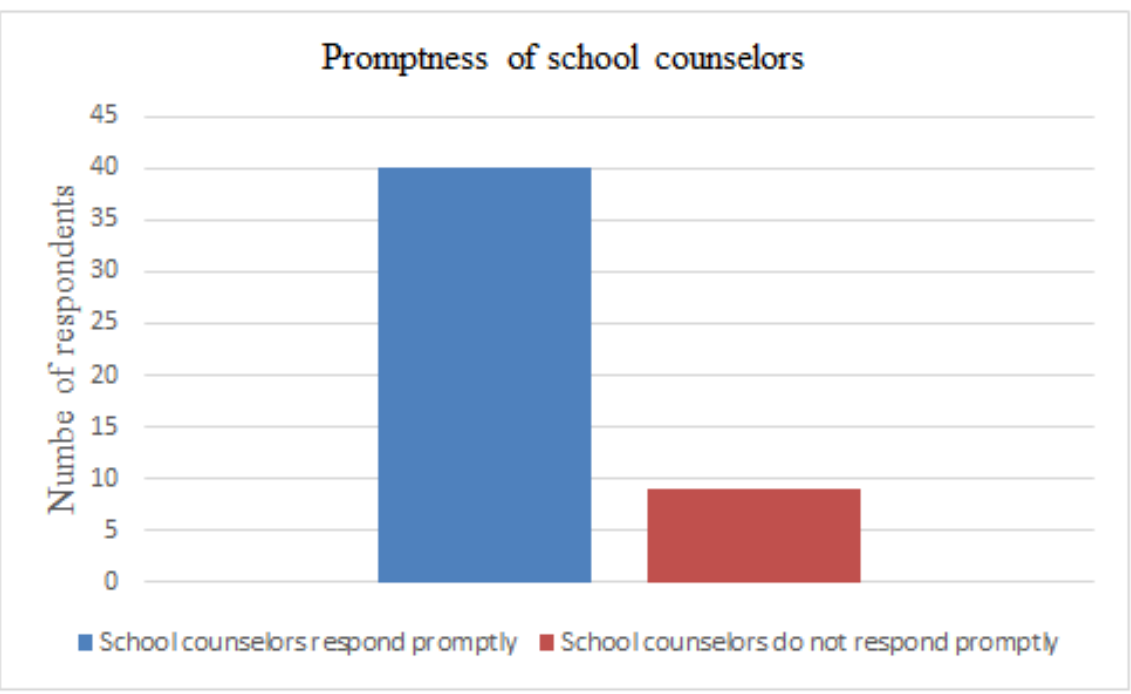

Figure 6: Promptness of school counselors

Shi, Liu, and Leuwerke (2014) depict that it is vital for the school counselors to respond promptly to the learners' needs and requests to avoid resent and subsequent drop out among students. Further, promptness ensures that learners are focused and have the urge to pursue a certain career. As such, it is inherent to ensure that school counselors have access to appropriate and sufficient resources to address the varied needs of their learners. If the counselors fail to respond promptly to the needs of the students; learners may develop a negative attitude to learning, guidance, and subsequent career selection. Hence, leading them to make poor career decisions, which might adversely impact their futures?

\section{Dependability to keep promises}

School counselors often have varied, specialized, and unique training needs to adequately serve the learners in their respective jurisdictions (Kozlowski \& Huss, 2013). According to Kozlowski and Huss (2013), school counselors ought to have proficient skills to develop programs, collaborate practices, and ensure better referral procedures. As such, the counselor needs to be trusted and dependable so that their learners can be open to them regarding what they want to do in the future. Once the learners realize that their school counselors are dependable and can keep promises, they will always seek aid with regards to their career selection. The current study participants indicated that majority of the counselors are dependable and can keep promises. Figure 7 indicates the dependability of the school counselors.

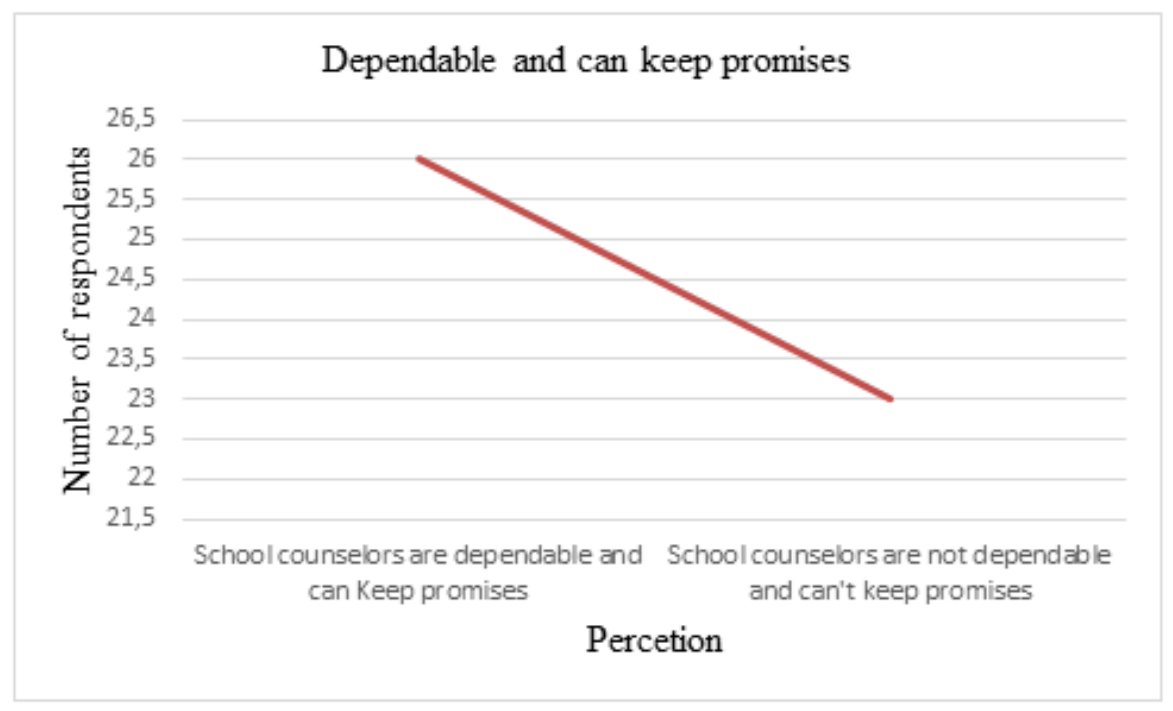

Figure 7: Dependable and can keep promises

As indicated from figure 7, there was a slight variation with regards to the number of students that perceive schoolers are dependable and those that can keep promises and those that are not dependable and cannot keep promises. Basically, there were 26 participants who indicated that school counselors are dependable and can keep promises while 23 individuals indicated that they school counselors are not dependable and they do not keep promises. These responses indicated 53\% and 47\% respectively. These findings were in line with the results obtained from Zaichenko and Vinokurov's (2018) study, which implicated that the counselor's ability to keep promises augmented the 
perception of dependability and bolstered help-seeking behaviors among the students. As such, academic performance and alignment with career selection was significantly related to the aspect of career orientation. Thus, it is imperative for the school counselors to have the potential to exhibit dependability and keep promises to their learners.

\section{Robustness in vocational knowledge}

Educational interventions to career selection are often the responsibility of the school counselors. Career guidance if often a challenging task as students presents their urges to pursue different fields, which contradict their potentialities (Racene \& Dislere, 2013). As such, it is imperative for the school counselor to assess the potentials of the respective learners and guide them accordingly. Thence, the school counselors should have the much-needed knowledge about the different vocations, which their learners may come to seek help. Students have to see their counselors as well-endowed with knowledge regarding varied vocations so that they can develop trust and the quest to seek for advice. Yesilyaprak (2012) contend that due to vast globalization, school counselors need to have robust knowledge about different careers and their applicability in the current world. They ought to be conversant with the varied changes evinced in both the social and economic sphere so that they can equip learners with relevant knowledge about careers (Yesilyaprak, 2012). The current investigation revealed that majority of the students perceives their school counselors as knowledgeable about different vocations. Figure 8 indicates how the learners perceive their school counselors with regards to their knowledge about careers.

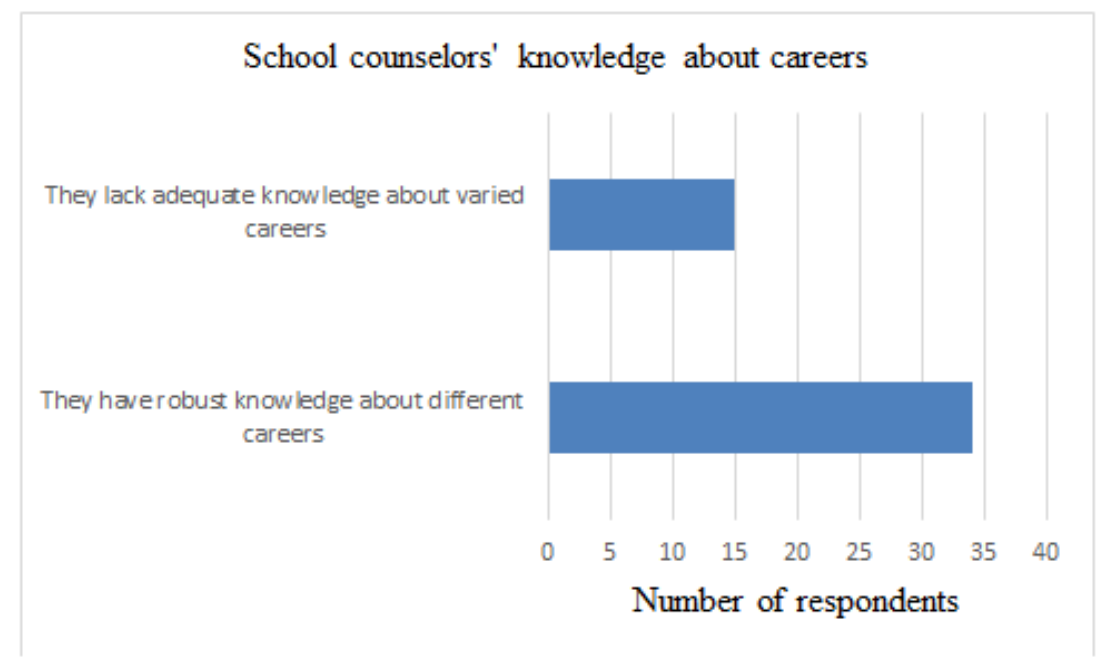

Figure 8: School counselors' knowledge about careers

As denoted, 34 of the students indicated that their school counselors have vast knowledge about the varied careers; hence, seek career help from them. Those that perceived the school counselors as lacking adequate knowledge about careers. These students represented $69.4 \%$ and $20.6 \%$ respectively. The findings of this study were culminated in Morgan, Greenwaldt, and Gosselin's (2014) study where the researchers studied the aspect of competency among school counselors in career counseling . According to Morgan et al. (2014), school counselors should always be aware of different career opportunities, be self-confident, consult their colleagues, and be updated with regards to technological developments to ensure noble decisions are attained when guiding their learners in career selection.

\section{Conclusion}

The study aimed to investigate the students' perceptions towards the counselors' role in career selection. Through case study design, the researcher focused on the case of three schools in Adana, Turkey; the sampled schools practiced counselor-assisted career selection. Using the self-report questionnaires, data were gathered from 60 students. Through descriptive analysis, the study revealed that all the learners agreed that school counselors participate in their career selection. However, as indicated by the findings of the current investigation, it is clear that students have different perceptions about their school counselors and whether to seek help with career decisions.

The findings revealed that the majority of the students agreed that school counselors are friendly and approachable to the majority of them. The study also showed that students recognize the counselors to an in-depth understanding of the different learners' viewpoints, and often respond promptly to the students' needs and requests regarding career selection. Further, the students perceive that the school counselors are dependable and objective when guiding the learners through career selection. Moreover, school counselors are professionals who have robust vocational knowledge; hence, the resolve to seek career guidance. 


\section{Recommendations}

Based on this study, it is evident that most students perceive counselors as highly educated, informed, objective, and experienced advisors during career selection. In this regard, the study recommends schools to consider having counselor-assisted career selection practices. However, further studies are also required to investigate measures of enhancing counselors' objectivity, experience, and expertise when guiding students during career selection. As such, school counselors ought to be trained and harness sufficient knowledge pertinent to the learners' viewpoints and needs to attain different careers desires.

The study also recommends a quantitative survey with a larger sample population since this research focused on qualitative techniques to conduct the investigation. There are other two approaches including quantitative and mixedmethods that could be used to answer the study objectives. Since we have used the qualitative technique, it is critical for the researcher to implement the remaining approaches to establish whether similar results are attained. Additionally, future research should explore this phenomenon among the learners of other institutions including universities to ascertain whether similar findings can be garnered. The current study focused on high school students' perspectives on the roles of school counselors pertinent to career selection. Therefore, it is prudent for the future studies to investigate the same conception using a different study populace; for instance, college or university learners.

\section{References}

Andronic, A., Andronic, R., Lepadatu, I., \& Tatu, C. (2013). Perceptions regarding the role of school counsellor in Romania a comparative approach. Procedia - Social and Behavioral Sciences, 84 (2013), 1124 - 1127.

Atici, M. (2014). Examination of School Counselors' Activities: From the Perspectives of Counselor Efficacy and Collaboration with School Staff. Educational Sciences: Theory \& Practice, 14(6), 2107-2120

Awinsong, M., Dawson, O., and Gidiglo, B.E. (2015). Students" Perception of the Role of Counsellors in the Choice of a Career: a study of the Mfantseman Municipality in Ghana. International Journal of Learning, Teaching and Educational Research 13(3), 79-99

Barden, S. M., Sherrell, R. S., \& Matthews, J. J. (2017). A National Survey on Multicultural Competence for Professional Counselors: A Replication Study. Journal of Counseling \& Development, 95(2), 203-212. doi:10.1002/jcad.12132

Bird, D.K. (2009). The use of questionnaires for acquiring information on public perception of counselling - a review of current knowledge and practice. Journal of Psychological Counselling, 9, 1307-1325.

Glessner, K., Rockinson-Szapkiw, A. J., \& Lopez, M. L. (2017). 'Yes, I can': testing an intervention to increase middle school students' college and career self-efficacy. Career Development Quarterly, 65(4), 315-325.

Goodman-Scott, E., \& Grothaus, T. (2017). School counselors' roles in ramp and pbis: A phenomenological investigation (Part two). Professional School Counseling, 21(1), 130-141. doi:10.5330/1096-2409-21.1.130

Hsieh, H., \& Shannon, S. E. (2005). Three approaches to qualitative analysis. Qualitative Health Research, 15, $1277-1288$. doi: $10.1177 / 1049732305276687$

Karatas, K. \& Kaya, I. (2015). An investigation of the perceptions of school administrators towards the roles and duties of school counselors. Eurasian Journal of Educational Research, 61, 181-198. http://dx.doi.org/10.14689/ejer.2015.61.10

Kozlowski, K.A., \& Huss, S. (2013). Training of school counselors. VISTAS Online, 53(4), 1-17

Lai-Yeung, S.W.C. (2014). The need for guidance and counselling training for teachers. Social and Behavioral Sciences. $113,36-43$

Malik, S.K., \& Kiran, Z. (2012). Students perception about the need of career counseling at university level. Edu. Tech. 52, 11417-11424.

Mapfumo, J., \& Nkoma, E. (2013). Freshmen: Guidance and counselling received in high school and that needed in university. International Journal of Scientific and Research Publications, 3(12), 1-10

Maxey, D., \& Kezar, A. J. (2016). Envisioning the faculty for the twenty-first century: moving to a mission-oriented and learner-centered model. New Brunswick, New Jersey: Rutgers University Press.

Morgan, L.W., Greenwaldt, M.E., \& Gosselin, K.P. (2014). School counselors' perceptions of competency in career counseling. The Professional Counselor, 4(5), 481-496 http://tpcjournal.nbcc.org

Nassaji, H. (2015). Qualitative and descriptive research: Data type versus data analysis. Language Teaching Research 2015, 19(2), 129-132

Nyamwange, C.B., Nyakan, P.O., and Ondima, P.C. (2012). Assessment of challenges facing secondary school guidance and counselling teachers in Nyamira district, Kenya. Journal of Education and Practice 3 (16), 41-47 
Oertle, K. M., \& O'Leary, S. (2017). The importance of career development in constructing vocational rehabilitation transition policies and practices. Journal of Vocational Rehabilitation, 46(3), 407-423. doi:10.3233/JVR-170877

Owino, E.A. (2013). An exploration of nature of guidance and counseling services in selected secondary schools in Eldoret municipality, Kenya. Journal of Emerging Trends in Educational Research and Policy Studies (JETERAPS) $5(1), 65-72$

Ozabaci, N. (2011). Turkish students' metaphorical conceptualisations of school counsellors. South African Journal of Psychology, 41(1), 29-37 https://doi.org/10.1177/008124631104100104

Palade, A., \& Constantin, C. (2012). The necessity of counselling and vocational orientation in students' career management. Bulletin of The Transilvania University of Brasov. Series V: Economic Sciences, 5(2), 61-68.

Pârvu, I., \& Mitran, P. C. (2017). Performance measurement of the counseling and vocational guidance activities implemented within pre-university education. Economics, Management \& Financial Markets, 12(2), 113-121.

Patton, W., \& McMahon, M. (2014). Career development and systems theory: connecting theory and practice. Rotterdam, The Netherlands: Sense Publishers.

Phelan, S. (2011). Case study research: Design and methods. Evaluation \& Research in Education, 24(3), 221-222, DOI: $10.1080 / 09500790.2011 .582317$

Racene, A., \& Dislere, V. (2013). A career development support programme for women in professional crisis situations. European Integration Studies, 6(7), 42-50. doi:10.5755/j01.eis.0.7.4183

Reardon, R.C., \& Lenz, J.G. (1999). Holland's theory and career assessment. Journal of Vocational Behavior 55, 102-113

Ridder, H. (2017). The theory contribution of case study research designs. Business Research, 10(2), 281-305. doi:10.1007/s40685-017-0045-z

Shi, Q., Liu, X., \& Leuwerke, W. (2014). Students' perceptions of school counselors: an investigation of two high schools in Beijing, China. The Professional Counselor Volume 4(5), 519-530 http://tpcjournal.nbcc.org

Shillingford-Butle, M.A., Patel, S.H., \& Ngazimbi, E.E. (2012). The role of the professional school counselor in reducing teacher anxiety, VISTAS, 58(4), 1-10

Snell Jr., W. E., Hampton, B. R., \& McManus, P. (2012). The impact of counselor and participant gender on willingness to discuss relational topics: development of the relationship disclosure scale. Journal of Counseling \& Development, 70(3), 409-416.

Stăiculescu, C., Livinţi, R., Stefan, L. R., Todea, S., \& Albu, N. (2017). Managing the need for career guidance and counseling for students case study - The Bucharest University of Economics Studies. Review of International Comparative Management / Revista De Management Comparat International, 18(2), 158-170.

Stefaniak, J.E., \& Tracey, M.W. (2015). An exploration of student experiences with learner-centered instructional strategies. Contemporary Educational Technology, 2015, 6(2), 95-112

Tang, M. (2008, October). Examining the application of Holland's theory to vocational interests and choices of Chinese college students. Journal of Career Assessment, 17(1), 86-98.

Todd Mckee, M., \& Caldarella, P. (2016). Middle school predictors of high school performance: A case study of dropout risk indicators. Education, 136(4), 515-529.

Todd, C. (2017). The art of counseling. Techniques: Connecting Education \& Careers, 92(1), 28-33.

Vaismoradi, M., Jones, J., Turunen, H., \& Snelgrove, S. (2016). Theme development in qualitative content analysis and thematic analysis. Journal of Nursing Education and Practice 6 (5), 100-110. DOI: 10.5430/jnep.v6n5p100

Yazan, B. (2015). Three approaches to case study methods in education: Yin, Merriam, and Stake. The Qualitative Report, 20(2), 134-152.

Yesilyaprak, B. (2012). The paradigm shift of vocational guidance and career counseling and its implications for Turkey: An evaluation from past to future. Educational Sciences: Theory \& Practice 12(1), 111-118

Yilmaz-Gozu, H. (2013). The effects of counsellor gender and problem type on help-seeking attitudes among Turkish high school students. British Journal of Guidance \& Counselling, 41(2), 178-192. doi:10.1080/03069885.2012.726346

Zaichenko, N. A., \& Vinokurov, M. V. (2018). Academic capital and the career orientations of high school students. Russian Education \& Society, 60(2), 187-201. 